\title{
Chapter 12 \\ Using Data for Decision-Making: From \\ Observations to Indicators and Other \\ Policy Tools
}

\author{
Matt Walpole, Melodie A. McGeoch, Philip Bubb and Neil Brummitt
}

\begin{abstract}
Previous chapters in this handbook have focused primarily on how to develop observing systems and generate biodiversity observations. Drawing on these foundations, this chapter explores the use of such data in decision-making processes. It reflects on what data might be used for, how it is packaged, what the challenges are and what to consider in getting it right. It is intended to be a thought-provoking look at insights gained in communicating biodiversity science for policy purposes over the last several years. With a particular focus on indicators, one of the most common forms in which observations are used by decision-makers, the chapter considers the context in which indicators are used and how they are developed. It explores the realities of indicator development and use, including some of the key challenges and ways around them. It also touches on assessments and assessment processes as another important tool linking science to policy.
\end{abstract}

Keywords Indicator development - Data use - Policy impact · Assessments

M. Walpole ( $₫)$. P. Bubb

United Nations Environment Programme World Conservation Monitoring Centre

(UNEP-WCMC), 219 Huntingdon Road, Cambridge CB3 0DL, UK

e-mail: Matt.Walpole@unep-wcmc.org

P. Bubb

e-mail: Philip.Bubb@unep-wcmc.org

M.A. McGeoch

School of Biological Sciences, Monash University, Melbourne, Victoria 3800, Australia e-mail: melodie.mcgeoch@monash.edu

N. Brummitt

Department of Life Sciences, Natural History Museum, Cromwell Road,

London SW7 5BD, UK

e-mail: n.brummitt@nhm.ac.uk

(C) The Author(s) 2017 


\subsection{Introduction}

Previous chapters in this handbook have focused primarily on how to develop observing systems and generate biodiversity observations. Drawing on these foundations, this chapter explores the use of such data in decision-making processes. It reflects on what data might be used for, how it is packaged, what the challenges are and what to consider in getting it right. It is intended to be a thought-provoking look at insights gained from communicating biodiversity science for policy purposes over the last several years. With a particular focus on indicators, one of the most common forms in which observations are used by decision-makers, the chapter considers the context in which indicators are used and how they are developed. It explores the realities of indicator development and use, including some of the key challenges and ways around them. It also touches on biodiversity assessments and assessment processes as another important tool linking science to policy.

\subsubsection{What Are Indicators?}

Indicators are communication and decision-support tools. They tell a story to help stimulate and guide action. They are part of a process, not an end in themselves. A useful definition of an indicator is that used by the Biodiversity Indicators Partnership (BIP; http://www.bipindicators.net) as 'a measure based on verifiable data that conveys information about more than itself' (Biodiversity Indicators Partnership 2011). In essence, this is saying that data requires an external context in which to be delivered before it becomes valuable as an indicator. As noted by Bubb (2013, p. 403) 'indicators are purpose-dependent and so the interpretation or meaning of the data depends on the issue being examined'.

Consider some examples. One form of biodiversity observation, or measure, may be about land cover, or the size of a patch of particular habitat. Collected regularly over space and time, these observations can be amassed to create a variable (or metric) about habitat or ecosystem extent. An example might be forest extent. At this stage, this is not an indicator, it is simply data telling us about itself, i.e., change in forest extent. The way that the data are used, alone or combined with other ancillary information, will determine its role as an indicator. For example, the data could be used to generate an analysis of rates of forest loss (or gain) that could be used to track progress towards a target to reduce such as rates of loss (or one to achieve certain levels of forest restoration). Alternatively, the data could be transformed into measures of carbon storage in forests that could be used to track progress towards a target concerned with improving biodiversity contribution to carbon stocks. Alternatively, in combination with information on the location of 
protected areas, the data could be used to say something about how effective protected areas are at conserving forests, and to track progress towards a target concerned with improving the effectiveness of conservation interventions like protected areas.

In this example, one kind of observation (of forest cover), when collected over time, creates a change variable (forest extent) which, depending on the context, can underpin a range of different indicators. This example is not fictional-all of these targets and indicators exist in the context of the Convention on Biological Diversity (CBD). Nor is it unique; existing observations on populations, species and ecosystem services can also all be used in various ways to create multiple indicators for different purposes. More on this later.

A good indicator has to be scientifically valid (based on reliable, verifiable data and with a clear relationship between the indicator and its purpose), sensitive to change in the issue of concern within appropriate timescales and spatial scales, and produced on a sufficiently regular basis using repeatable methods to track change over time. A successful indicator is one that is actually used to support decision-making (Biodiversity Indicators Partnership 2011).

In order for an indicator to be useful to the non-specialist it usually requires a storyline, a narrative that interprets the meaning of the data on which it is based. The annually updated Aichi Passport (Chenery et al. 2013; http://www. bipindicators.net/resource/aichipassport) contains examples of a number of indicators combining time series data (usually presented as a line graph, but sometimes in other ways such as a pie chart or change map) with narrative storylines explaining what they mean in the context of the particular Target to which they relate. At a national level, the UK government's annual biodiversity indicators publication (DEFRA 2013; available from https://www.gov.uk/government/ publications/biodiversity-indicators-for-the-uk) includes a traffic light scheme for illustrating which metrics (termed measures in this publication) indicate improvement, no change, or decline. The Millennium Development Goals (MDG) Annual Reports (http://www.un.org/millenniumgoals/reports.shtml) provide another example of how indicators can be communicated as a combination of data and storylines. Importantly, indicators are designed to effectively communicate information that is relevant to one or more policy objectives and to do so in a way that translates raw data into clear messages. Packaged and communicated in the right way, information on biodiversity change can have real policy impact.

\subsubsection{The Policy Context for Biodiversity Indicators}

Ultimately, the value of biodiversity observations and observing systems of the kind supported and promoted by GEO BON is in their use. There are a variety of policy contexts in which biodiversity indicators are required to assist in monitoring, assessing and reporting progress towards targets in plans and strategies. 
At the international level the pre-eminent biodiversity context is the CBD and the collective commitments that Parties (primarily national governments) have made. The adoption in 2002 of the 2010 Biodiversity Target led to considerable effort to identify and develop indicators at a global level (Walpole et al. 2009). At the same time, Parties to the CBD were expected to report periodically on their own contributions and progress towards achieving this collective goal. In 2010 a new Strategic Plan for Biodiversity 2011-2020 was adopted by Parties to the CBD, including the twenty Aichi Targets (http://www.cbd.int/sp/). In 2014 the first national reports of progress in implementing the strategic plan, and the first global assessment of progress towards these targets was delivered (Leadley et al. 2014; Tittensor et al. 2014), with further reporting and assessment expected later in the decade.

There are a range of other global biodiversity-related conventions with strategies, goals and targets that require indicators of both national and international implementation and progress, including the Convention on International Trade in Endangered Species of Wild Fauna and Flora (CITES; www.cites.org), the Convention on the Conservation of Migratory Species of Wild Animals (CMS; http://www.cms.int/) family and the Ramsar Convention on Wetlands of International Importance (www.ramsar.org). More broadly, biodiversity and ecosystem service indicators are used in international development contexts, most notably to track progress towards the Millennium Development Goals up to 2015 (United Nations 2013; Sachs et al. 2009), and the Sustainable Development Goals subsequently (http://unstats.un.org/sdgs/). Besides these global agreements, there may be regional commitments for which governments are required to report, such as the EU Biodiversity Strategy (European Union 2011).

Nationally, biodiversity indicators are required to track progress towards national goals and targets including those defined within National Biodiversity Strategies and Action Plans (NBSAPs) (http://www.cbd.int/nbsap/; http:// nbsapforum.net/), as well as for reporting against international commitments. They may be used more broadly, for public outreach and communication or for specific sectoral plans and policies, as well as for biodiversity management and threat reduction. In an innovative example, near real time, publically available satellite data on deforestation in Brazil has been used to boost law enforcement efforts that has yielded huge reductions in deforestation rates over the past decade (Secades et al. 2014). They are also likely to be useful in the context of national development planning and, increasingly, in national accounting to provide more balanced, inclusive measures of national wealth and well-being.

It is also worth noting that, for various conservation investment stakeholders, biodiversity indicators are essential to aid evaluation of the impact and success of conservation investment actions (Stephenson et al. 2015). 


\subsection{Developing Indicators}

Developing indicators successfully involves a number of steps. A useful tool for this process is the biodiversity indicator development framework (Fig. 12.1). This covers ten steps grouped into three areas: Purpose (actions needed for selecting successful indicators), Production (steps essential to generate indicators) and Permanence (mechanisms for ensuring indicator continuity and sustainability).

Fig. 12.1 Biodiversity indicator development framework. (Source Biodiversity Indicators Partnership 2011)

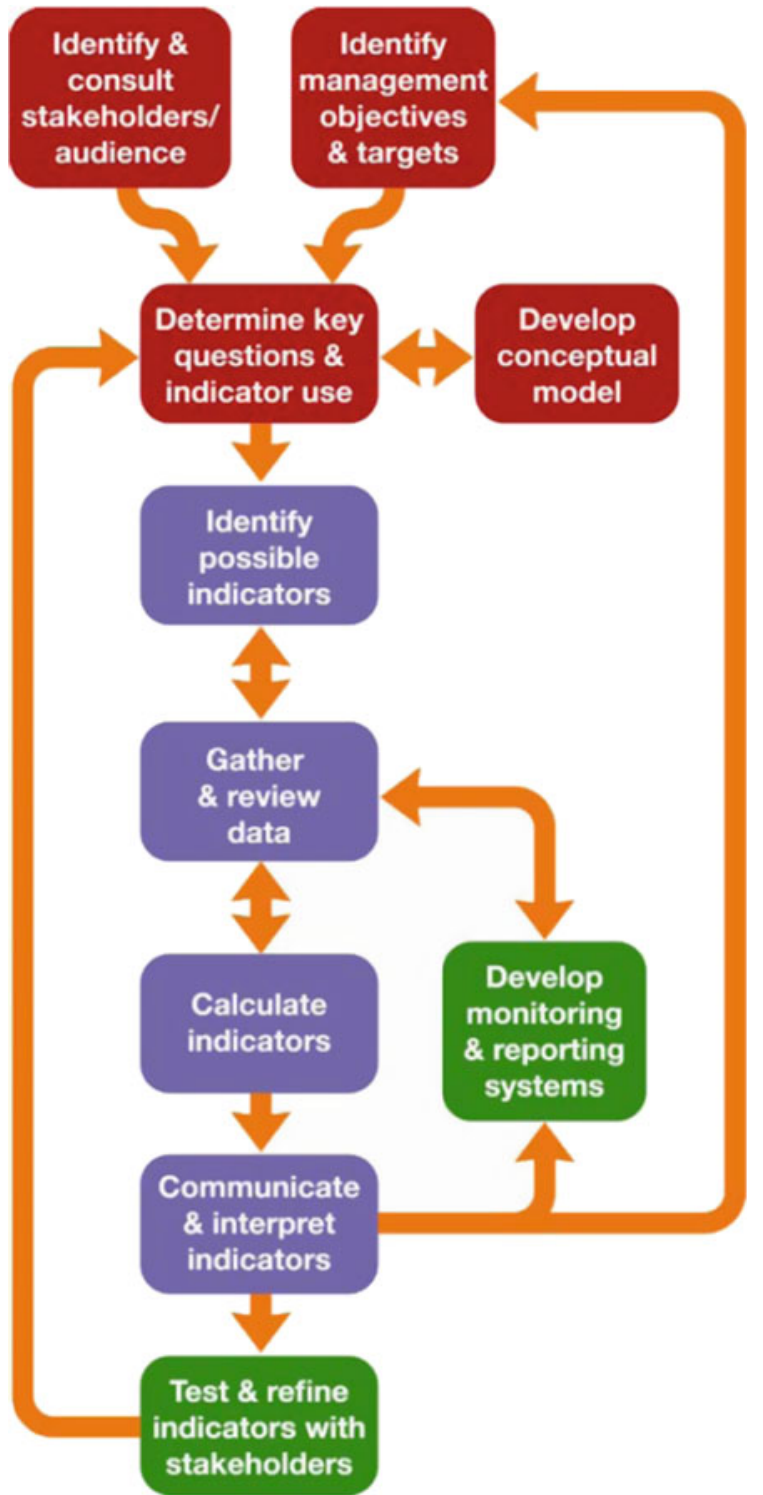




\subsubsection{Starting with the Question}

How are good biodiversity observations turned into good indicators? The key, in fact, is not to start with the data, but rather with the question that decision-makers need answering. Such questions can be framed in the context of explicit policies, plans, goals and targets. Are we on track to meet a particular target? Is our policy moving things in the right or wrong direction? These questions determine the kinds of indicators required and the kinds of data needed to produce them.

Once the key questions are defined, it is possible to consider which metrics would most adequately address these questions and what the most robust methods would be to deliver those metrics. It is also important to consider how they would be interpreted and what possible misinterpretation or bias might result.

\subsubsection{Then Find the Data}

Whilst the theory of indicator development appears straightforward, there are often significant challenges, with data availability (in particular consistent trend data with reliable baselines) being one. As an example, during the fourth round of national reporting to the CBD in 2010, Parties were encouraged to use indicators and yet few presented data or figures as part of their storylines. When surveyed, almost half of respondents indicated that they did not have, or did not know whether their country had, indicators relevant to the CBD (Bubb 2013).

This may not be the full story - many countries may have other sources of data that are not recognised or readily available. For those countries that did report national indicators, only $15 \%$ noted that source data was primarily obtained from dedicated biodiversity monitoring systems. It was far more common for data to be sourced from monitoring systems developed for other purposes and from other sectors (such as forestry, agriculture or fisheries), or from academic research, surveys and assessments (recognising that one-off, time-bound studies are more useful in assessment processes than for indicators). Around $10 \%$ obtained data from external, regional or global sources (Bubb 2013).

This illustrates an important point. Mobilising such existing data, which may come from a wide range of different types of organisation including universities, NGOs, government agencies and the private sector, and from a range of sectors, can be a practical first step (see Box 12.1 for an international example). A number of countries which were hitherto lacking biodiversity indicators have subsequently used this approach to develop national biodiversity indicator reports.

\section{Box 12.1. From Ground Zero to an Indicator for Biological Invasions}

When the 2010 Biodiversity Target was set calling for an indicator of trends in invasive alien species there was no obvious option at hand. At the time 
there were no invasion indicators that had been developed for reporting at a global scale (Genovesi et al. 2013). There were many sources of information, but no collated body of data with global coverage on which species were where, and what impact they were having, particularly not for a range of taxonomic groups (McGeoch et al. 2012). Apart from many local case studies and a few regional ones (notably for Europe) there were also very few data on changes in the numbers of species threatening biodiversity over time.

The solution was to tackle the problem from three angles (McGeoch et al. 2010). First, using an operational definition that distinguished alien from invasive species (McGeoch et al. 2012), a stratified, random subset of countries was chosen to calculate the number of invasive species per country. This provided a robust, representative baseline measure of invasion pressure on countries that can now be tracked over time. Second, the well-known IUCN Red List Index (http://www.bipindicators.net/rli/2010; Butchart 2008) was used to illustrate trends in the extinction risk of a subset of species threatened by invasive species. Finally, information on policy trends relevant to invasion was used to indicate how countries were responding to the problem.

In sum, by using a combination of systematic data collation, adaptation of an existing indicator, and data on policy trends, an informative indicator for biological invasion was born.

Certain metrics can be used to create multiple indicators for different purposes, as illustrated earlier for forest extent (see also Box 12.2). This demonstrates the value and importance of focusing on the key metrics, or Essential Biodiversity Variables (EBVs; Pereira et al. 2013) that, when cut in certain ways and/or combined with ancillary data, can provide the most information on biodiversity change. Indicators for many of the Aichi Targets can be derived from a relatively small set of such metrics (Geijzendorffer et al. 2016; for an example, see Fig. 1.2).

Equally, where metrics can be standardised across scales, there is great potential for efficiency. Although national priorities are generally to develop indicators for specific national needs (including national goals and targets), there is a lot to be said for exploring and enhancing harmonised indicator use as a means of (i) increasing the availability of data for tracking progress towards broader scale, regional and global goals and targets and (ii) unlocking the value of global data sets, such as those in products derived from satellite remote sensing, for wider national use (Han et al. 2014).

\section{Box 12.2. Indicator Pragmatism: The Living Planet Index}

The Living Planet Index (LPI) is a metric of aggregate change in vertebrate population abundance over time in reference to a baseline year at which the index is set at a value of 100 (Loh et al. 2005; Collen et al. 2009). It is built up 
from individual population time series sourced from published and grey literature. The global database currently runs into thousands of such time series, and the index is calculated from a 1970 baseline to the current day.

The global LPI, like many other metrics used to underpin indicators (Walpole et al. 2009) is not perfect. The data it is built upon are patchy both taxonomically and geographically, being particularly rich in data from bird populations and temperate regions (Collen et al. 2008, 2009), although the construction of the index attempts to offset these imbalances.

Despite this, it has significant strengths as an indicator in a number of ways. First, it taps into a vast resource of existing data, and so is cost effective. Population abundance, for vertebrates at least, is one of the most commonly collected measures, both in discrete, time-bound studies and from continuous monitoring. Second, it tells a simple, easily understood message of overall, aggregate change. The LPI has achieved prominence as a tool for communicating global biodiversity change to the public via its central role in WWFs periodic Living Planet Report (WWF 2012). Third, it can be cut in various ways to answer different questions and provide indicators for different policy targets. From the global dataset it is relatively simple to draw out subset analyses, or cuts, of the LPI focusing, for example, on wetland-dependent species (of relevance to the Ramsar Convention) or migratory species (of relevance to the CMS) or harvested species (of relevance to sustainable use and human wellbeing concerns). Fourth, it can be improved with new data sources. Knowing where the data gaps are enables a focus on filling those gaps, whether through unlocking more existing data or by investing in new monitoring. Fifth, it can be applied in different settings and different scales. A national LPI built from within-country studies of population abundances of different species is simple and cost-effective to construct. Moreover, the same approach can be applied to create an index of aggregate change in habitat extent, as has recently been created for wetland extent for the Ramsar Convention (Dixon et al. 2016).

In the same way, harmonising the use of metrics across policy contexts is not only an efficient use of resources but also creates greater awareness and potential for mainstreaming biodiversity into other development sectors. Globally, metrics of forest change, fisheries, threatened species and protected area coverage have been used to provide indicators in the context of both the CBD and the Millennium Development Goals. Nationally, there are increasing efforts to incorporate 'natural capital' (including biodiversity and ecosystem services) into national accounts (King et al. 2015). The more that biodiversity data can be used in these contexts, the greater impact it will have on decision-making. 


\subsubsection{Trade-Offs and Compromises Between Data Availability and Policy Needs}

In an ideal world, data coverage would be universal, observations would be regularly repeated and the indicators derived would be tightly linked to the targets or policy processes for which they were being used, so that even slight changes would tell a decision-maker in a timely manner what action was required to keep things on track. In reality, it is never this simple. Data are patchy in space, time and thematic/taxonomic coverage. Even where gaps can be filled, detecting meaningful (significant) change is not straightforward, ascribing causes and appropriate action less so, and sustaining consistent data collection over the long term difficult to resource. Moreover, policy targets are not always determined with suitable metrics and indicators in mind, such that their interpretation and translation for monitoring purposes can be difficult.

This does not mean, however, that we cannot develop useful indicators that influence policy and action, if we remember that indicators are at heart a communication tool, and if we are very clear about what they are communicating. Consider the 2010 Biodiversity Target and the metrics used to track progress towards it. The data were patchy and far from perfectly aligned to the needs of the headline indicators (Walpole et al. 2009), but were able to tell a compelling story around pressures, state and responses at global scale (Butchart et al. 2010) that alerted people to a need for greater action and fuelled the debate that led to a more comprehensive, explicit Strategic Plan for 2011-2020.

Part of the challenge for 2010 was the relatively late stage at which indicators began to be considered. Although the 2010 Biodiversity Target was agreed in 2002, the headline indicators were not agreed until 2006. Concerted effort to populate a suite of indicators only took place in the last few years before the target deadline, meaning that indicators had to be adapted from what was available (see Box 12.1 for an example of what was achieved). Post-2010 the need to develop indicators early in the process, in tandem with targets, has been recognised. Yet we are still largely retro-fitting indicators to targets rather than creating targets with indicators in mind. Given that few of the Targets are quantitatively specific, indicators can largely only communicate whether things are heading in the right direction or not (Tittensor et al. 2014). This is still policy relevant, however, and of great value to decision-makers in pointing to where things need particular attention.

Developing indicators can be a journey of gradual improvement. Even if existing data quality and quantity are not optimal, using what we have can be a major incentive to leverage governments, scientists and data providers to do better if it stimulates scrutiny and debate about the robustness of the data and its suitability for indicators in the context in which it is being used. This has the potential to stimulate investment and improvement in both data and indicators. Indeed, within the GEO BON community such scrutiny and investment has yielded innovate new candidate indicators, based on several of the EBVs, that make use of state of the art modelling techniques, large datasets and remote sensing (GEO BON 2015). 
The Biodiversity Indicator development Framework (Fig. 12.1) includes steps and feedback loops concerned with testing and refining indicators in line with the policy questions posed of them.

\subsection{Beyond the Data-Partnerships and Other Enabling Factors}

Data gaps and limitations are not the only challenges for developing and using indicators, so that focusing solely on improving observing systems will not guarantee more evidence-informed decision-making. A lack of funding and human capacity particularly for data integration, analysis and reporting is a widespread constraint, hindered further by a lack of awareness, interest, and political will (Bubb 2013).

The fact that data are often derived from multiple institutions signals the importance of both a co-ordinating body and a functioning network or partnership within a country. The BIP (see Box 12.3) is a global example of the kind of partnership approach to indicator development that could be taken nationally, to bring together the best data sources and providers covering the range of indicator information needs. Most important, however, is a coordinating body, a national office or institution responsible for co-ordinating analysis and communication of biodiversity data (Bubb 2013). Many countries have government bodies for related sectors such as fisheries, forests, etc., but not often for biodiversity as a whole. Those which do, including China, South Africa, Brazil and Mexico, are able to develop and report indicators regularly as an integral part of government processes.

It is also crucial to engage decision-makers from the outset. Whilst starting with the question is key, having those asking the questions owning the process is equally important. A key player in any network will be the government statistical office which in adopting particular metrics signifies an official stamp of approval and increases the likelihood of government use, as well as credibility and uptake more widely beyond environment ministries and the biodiversity community.

\section{Box 12.3. The Biodiversity Indicators Partnership}

The CBD-mandated Biodiversity Indicators Partnership is a global initiative to promote and coordinate development and delivery of biodiversity indicators in support of the CBD, Multilateral Environmental Agreements (MEA), IPBES, national and regional governments and a range of other sectors. The Partnership brings together over forty organisations, including UN agencies, NGOs, universities and research bodies, working internationally on indicator development to provide the most comprehensive information on biodiversity and related trends worldwide. The BIP was originally established in 2007 to assist in compiling indicators to track progress towards the 2010 Biodiversity 
Target. This built on earlier work under the CBD to define 'headline indicators' for the 2010 Target and of the wider academic community to explore the state of the science of biodiversity indicators and to identify promising avenues (Balmford et al. 2005 and related papers in the same journal special issue arising from a Royal Society discussion meeting on "monitoring wild nature for the 2010 target").

The BIP partners provided a range of metrics focusing on biodiversity and ecosystem service trends, pressures and threats, and responses. Some 31 time series metrics were gathered. Not all of the CBD headline indicators were populated (Walpole et al. 2009), but this still represented a large increase in available data for the Third Global Biodiversity Outlook in 2010 compared to its predecessor in 2007 prior to the formation of the BIP.

Post-2010, the BIP has reoriented to the Aichi Targets and a focus on 2020. The partnership is strengthening to include a deeper and a wider breath of data providers. As a result, the BIP was able to deliver a first indicator-based analysis of progress towards the Aichi Targets using a larger number of time series metrics than in 2010 (Tittensor et al. 2014). The partnership also serves to raise awareness of the Targets amongst the observing community, creates links to other processes and agreements requiring indicators, and provides opportunities to share global methods and metrics with national governments and indicator practitioners to help develop capacity and to harmonise across scales.

The BIP is a complementary mechanism to GEO BON. Whilst GEO BON focuses on improving biodiversity observations that can be used in policy tools such as indicators, the BIP focuses on compiling and delivering those indicators for policy users. The two are mutually supporting and closely linked, with several organisations participating in both networks. Individuals from each network are also represented in the governance structures of the other.

\subsection{A Word on Assessments}

Indicators can be used in various ways and in various products, including assessments. Whilst indicators tend to be thought of as relatively continuous monitoring tools, assessments are more punctuated-one-off or periodic activities intended to draw together the best available evidence with which to answer a set of specific questions. In some cases these may focus on progress towards policy targets, as is the case with the CBD's periodic Global Biodiversity Assessment, which is heavily based on indicators. In others they may be more focused on understanding past and potential future change in a key thematic or sectoral field. The Millennium Ecosystem Assessment is a good example - it amassed an evidence base to explore how and why the world's ecosystems and the benefits they provide to society have 
changed over time, and constructed some future scenarios of how the world might look given certain broad policy choices. The International Assessment of Agricultural Knowledge, Science and Technology for Development (IAASTD 2009) is another example of a global assessment designed to answer specific policy questions, in this case relating to reducing hunger and improving nutrition in socially and environmentally sustainable ways.

Since its inception in 2012, the Intergovernmental Platform on Biodiversity and Ecosystem Services, IPBES, has provided a platform for delivering a range of thematic, regional and global assessments related to biodiversity and ecosystem services. In 2015, IPBES initiated, in response to requests from governments and non-governmental stakeholders, a set of regional assessments of biodiversity and ecosystem services in Africa, the Americas, Asia-Pacific, and Europe and Central Asia, which will be using indicators drawing from observations. In 2016, IPBES launched a global assessment which will draw information from the regional assessments. It will be key to select observations and indicators which allow comparisons among and within regions as well as aggregation at the global level.

Whilst assessments draw on diverse sources of information, spatio-temporal biodiversity and ecosystem service metrics are an important element, not only for revealing past trends and current status, but also, where these can be modelled, for exploring plausible future scenarios (Collen and Nicholson 2014; Newbold et al. 2015). Yet, as with indicators, assessments can fail as a communication and decision-making tool for reasons unrelated to the data and observations upon which they are built.

Assessments tend to be ignored if they are not undertaken with sufficient user engagement. In that regard they are best conceived of as a process rather than purely as a product - the key messages, synthesis and technical and regional reports commonly delivered by assessments are the culmination of, not the starting point for, communication and engagement. Those assessments which have had the most significant policy traction tend to be those that have had 'client' involvement from the outset (often governments or intergovernmental bodies).

Examples:

- The 2010 Global Biodiversity Outlook (SCBD 2010), requested by Parties to the $\mathrm{CBD}$, contributed to renewed, more explicit, more tangible commitments from the world's governments in the form of the Strategic Plan for Biodiversity 2011-2020 SP including the Aichi Targets.

- The UK National Ecosystem Assessment (2011), called for by the UK government, provided a significant part of the information base for England's Natural Environment White Paper, 2011, which included commitments to invest in ecosystem services and natural capital locally whilst exploring means to embed natural capital into accounting processes nationally.

Assessments with a clear audience who are shaping the questions it asks and who feel part of the process get noticed. It also helps to have policy champions in government (and preferably beyond the environment sector) who can open doors 
and help to 'sell' the assessment to a broader or more influential audience. Assessments that are built into (or align correctly with) planning processes also have greater impact since this ensures that their findings are delivered at the right time when they can be used in new or revised policy.

\subsection{Summing up}

\subsubsection{Take Home Messages}

This chapter has considered how biodiversity and related observations generated and curated using the kinds of methods, structures and processes promoted by GEO BON and described elsewhere in this book, may be used within policy-making processes to influence decisions that impact on biodiversity, with a particular focus on indicators. Packaged and communicated in the right way, information on biodiversity change can have real policy impact regardless of scale.

Successful examples all rely on the kinds of engagement between scientists/data providers and policymakers described in this chapter, using data to provide a service to decision-makers, with the process and delivery mechanism defined with and by those decision-makers. Indicators, and assessments, are potentially very powerful policy tools, but in all cases it is crucial to begin with the questions, not the data and to ensure policy-maker buy-into the process. When it comes to the data, a lot can be achieved by first using what is there with an eye to how it can be improved and important gaps filled. This may be by mobilising currently inaccessible existing data before investing in new observing systems, and can involve multiple partners from a range of fields. Nevertheless, however good the data, information management can be a major bottleneck to progress in delivering timely, relevant and comprehensive products; ensuring adequate co-ordination of the process and management of the data, often through a centralised body, should not be overlooked.

\subsubsection{Where to Go for More Information and Support}

- The BIP provides various resources via its website www.bipindicators.net, including guidance documents, indicator fact sheets and national case studies as well as the Aichi Targets Passport, an annual indicator update also available as a smart phone app.

- The CBD (www.cbd.int) and the NBSAP Forum (www.nbsapforum.net) both include resources for planning, including data and indicator use.

- IPBES and Future Earth both have working groups focusing on data, monitoring and indicators, the latter helping to define the scientific criteria for indicator development. 
- NatureServe have developed a Biodiversity Indicators Dashboard (http:// dashboard.natureserve.org) which showcases how global datasets can be disaggregated for national use, utilising creative visualisation methods to bring the data alive.

- GEO BON includes a cross-cutting working group on indicators, which draws representation from each of the other GEO BON working groups, as well as additional membership from relevant organisations and individuals worldwide. The group's objectives include:

(a) Ensuring the GEO BON community of practice is aware of and able to respond to user needs, both in terms of information to support indicators and capacity to generate such information, at national, regional and global scales,

(b) Incorporating biodiversity information and analyses from GEO BON into indicator-based policy products designed and delivered to meet user needs,

(c) Linking GEO BON to existing initiatives that improve information delivery to policy users, such as the Biodiversity Indicators Partnership (BIP), and

(d) Helping to communicate the value of GEO BON to end users.

Open Access This chapter is distributed under the terms of the Creative Commons Attribution-Noncommercial 2.5 License (http://creativecommons.org/licenses/by-nc/2.5/) which permits any noncommercial use, distribution, and reproduction in any medium, provided the original author(s) and source are credited.

The images or other third party material in this chapter are included in the work's Creative Commons license, unless indicated otherwise in the credit line; if such material is not included in the work's Creative Commons license and the respective action is not permitted by statutory regulation, users will need to obtain permission from the license holder to duplicate, adapt or reproduce the material.

\section{References}

Balmford, A., Crane, P., Dobson, A., Green, R. E., \& Mace, G. M. (2005). The 2010 challenge: Data availability, information needs and extraterrestrial insights. Philosophical Transactions of the Royal Society B: Biological Sciences, 360, 221-228.

Biodiversity Indicators Partnership. (2011). Guidance for national biodiversity indicator development and use (40 pp). Cambridge, UK.: UNEP-WCMC. http://www.bipindicators. net/LinkClick.aspx? fileticket=brn\%2FLxDzLio\%3D\&tabid=157

Bubb, P. (2013). Scaling up or down? linking global and national biodiversity indicators and reporting. In B. Collen, N. Pettorrelli, J. E. M. Baillie, \& S. M. Durant (Eds.), Biodiversity monitoring and conservation: bridging the gap between global commitment and local action (464 pp). Oxford, UK: Wiley-Blackwell.

Butchart, S. H. M. (2008). Red List indices to measure the sustainability of species use and impacts of invasive alien species. Bird Conservation International, 18, 245-262.

Butchart, S. H. M., Walpole, M., Collen, B., van Strien, A., Scharlemann, J. P. W., Almond, R. E. E., et al. (2010). Global biodiversity: Indicators of recent declines. Science, 328, 1164-1168. 
Chenery, A., Plumpton, H., Brown, C. \& Walpole, M. (2013). Aichi targets passport (2013 ed., 90 pp). Cambridge, UK: UNEP-WCMC. Download the Aichi targets passport indicator factsheets here: http://www.bipindicators.net/LinkClick.aspx?fileticket=-YdK-Zxv4g\%3d\&tabid=349)

Collen, B., Loh, J., Whitmee, S., McRae, L., Amin, R., \& Baillie, J. E. M. (2009). Monitoring change in vertebrate abundance: The living planet index. Conservation Biology, 23, 317-327.

Collen, B., \& Nicholson, E. (2014). Taking the measure of change. Science, 346, 166-167.

Collen, B., Ram, M., Zamin, T., \& McRae, L. (2008). The tropical biodiversity data gap: Addressing disparity in global monitoring. Tropical Conservation Science, 1, 75-88.

DEFRA. (2013). UK biodiversity indicators in your pocket 2013: measuring progress towards halting biodiversity loss (47 pp). London, UK: Department for Environment, Food and Rural Affairs. http://jncc.defra.gov.uk/pdf/BIYP_2013.pdf

Dixon, M. J. R., Loh, J., Davidson, N. C., Beltrame, C., Freeman, R., \& Walpole, M. (2016). Tracking global change in ecosystem area: The wetland extent trends index. Biological Conservation, 193, 27-35.

European Union. (2011). The EU biodiversity strategy to 2020 (28 pp). Luxembourg: Publications office of the European Union. http://ec.europa.eu/environment/nature/info/pubs/docs/ brochures/2020\%20Biod\%20brochure\%20final\%20lowres.pdf

Geijzendorffer, I. R., Regan, E., Pereira, H. M., Brotons, L., Brummitt, N. A., Gavish, Y., Haase, P., et al. (2016). Bridging the gap between biodiversity data and policy reporting needs: An essential biodiversity variables perspective. Journal of Applied Ecology, 53, 1341-1350. doi:10.1111/1365-2664.12417

Genovesi, P., Butchart, S. H. M., McGeoch, M. A., \& Roy, D. B. (2013). Monitoring trends in biological invasion, its impact and policy responses. In: B. Collen, N. Pettorelli, J. E. M. Baillie \& S. M. Durant (Eds.), Biodiversity monitoring and conservation: bridging the gap between global commitment and local action (pp. 138-158). Cambridge, UK: Wiley.

GEO BON. (2015). Global biodiversity change indicators (14 pp). Leipzig: GEO BON.

Han, X., Smyth, R. L., Young, B. E., Brooks, T. M., de Lozada, A. S., Bubb, P., et al. (2014). A biodiversity indicators dashboard: Addressing challenges to monitoring progress towards the Aichi biodiversity targets using disaggregated global data. PLOS ONE, 9(11), e112046.

IAASTD. (2009). Agriculture at a crossroads: Synthesis report (104 pp). Washington, D.C., USA: Island Press.

King, S., Wilson, L., Dixon, M., Brown, C., Regan, E., Blaney, R., et al. (2015). Experimental biodiversity accounting as a component of the system of environmental-economic accounting experimental ecosystem accounts (SEEA-EEA). Cambridge, UK: UNEP-WCMC.

Leadley, P. W., Krug, C. B., Alkemade, R., Pereira, H. M., Sumaila U. R., Walpole, M., et al. (2014). Progress towards the Aichi biodiversity targets: An assessment of biodiversity trends, policy scenarios and key actions (500 pp). Technical Series No. 78, Montreal, Canada: Secretariat of the Convention on Biological Diversity.

Loh, J., Green, R. E., Ricketts, T., Lamoreux, J., Jenkins, M., Kapos, V., et al. (2005). The living planet index: Using species population time series to track trends in biodiversity. Philosophical Transactions of the Royal Society B: Biological Sciences, 360, 289-295.

McGeoch, M. A., Butchart, S. H. M., Spear, D., Marais, E., Kleynhans, E., Symes, A., et al. (2010). Global indicators of biological invasion: Species numbers, biodiversity impact and policy responses. Diversity and Distributions, 16, 95-108.

McGeoch, M. A., Spear, D., Kleynhans, E. J., \& Marais, E. (2012). Uncertainty in invasive alien species listing. Ecological Applications, 22, 959-971.

Newbold, T., Hudson, L. N., Hill, S. L. L., Contu, S., Lysenko, I., Senior, R. A., et al. (2015). Global effects of land use on local terrestrial biodiversity. Nature, 520, 45-50.

Pereira, H. M., Ferrier, S., Walters, M., Geller, G. N., Jongman, R. H. G., Scholes, R. J., et al. (2013). Essential biodiversity variables. Science, 339, 277-278.

Sachs, J. D., Baillie, J. E., Sutherland, W. J., Armsworth, P. R., Ash, N., Beddington, J., et al. (2009). Biodiversity conservation and the millennium development goals. Science, 325, 1502 1503 . 
Secades, C., O'Connor, B., Brown, C., \& Walpole, M. (2014). Earth observation for biodiversity monitoring: A review of current approaches and future opportunities for tracking progress towards the Aichi biodiversity targets (183 pp). CBD Technical Series No. 72, Montreal, Canada: CBD. http://www.cbd.int/doc/publications/cbd-ts-72-en.pdf

Secretariat of the CBD. (2010). Global biodiversity outlook 3 (94 pp). Montreal.

Stephenson, P. J., Burgess, N. D., Jungmann, L., Loh, J. O'Connor, S., Oldfield, T., et al. (2015). Overcoming the challenges to conservation monitoring: Integrating data from in-situ reporting and global data sets to measure impact and performance. Biodiversity, 16, 2-3.

Tittensor, D. P., Walpole, M., Hill, S. L. L., Boyce, D. G., Britten, G. L., Burgess, N. D., et al. (2014). A mid-term analysis of progress towards international biodiversity targets. Science, 346, 241-244.

UK National Ecosystem Assessment. (2011). Synthesis of the key findings (85 pp). Cambridge: UNEP-WCMC.

United Nations. (2013). The millennium development goals report 2013 (60 pp). New York, USA: UN. http://www.un.org/millenniumgoals/pdf/report-2013/mdg-report-2013-english.pdf

Walpole, M., Almond, R. E. A., Besancon, C., Butchart, S. H. M., Campbell-Lendrum, D., Carr, G. M., et al. (2009). Tracking progress toward the 2010 biodiversity target and beyond. Science, 325, 1503-1504.

WWF. (2012). Living planet report 2012: Biodiversity, biocapacity and better choices (160 pp). Gland, Switzerland: WWF. http://www.un.org/millenniumgoals/pdf/report-2013/mdg-report2013-english.pdf 